\title{
"A reputation like a scarlet robe": política pós-moderna e gênero em The secret gospel of Mary Magdalene
}

\author{
Ruan Nunes Silva ${ }^{1}$ \\ http://lattes.cnpq.br/8687409037870171
}

Resumo: Este artigo pretende estabelecer uma relação entre os campos da literatura e religião através da investigação do romance The Secret Gospel of Mary Magdalene, escrito pela inglesa Michèle Roberts. A partir de uma ótica que privilegia questões de gênero, o romance de Roberts desconstrói a figura de Maria Madalena ao criar uma história diferente a partir de textos gnósticos. Com isso, Roberts emprega estratégias pós-modernas e revela um entrelaçamento entre literatura e história como práticas discursivas.

Palavras-chave: Pós-modernismo; Gênero; Religião; Michèle Roberts.

Abstract: This article aims to establish a connection between the literary and religious fields by means of investigating the novel The Secret Gospel of Mary Magdalene, written by Michèle Roberts. From a standpoint which privileges questions of gender, Roberts' novel deconstructs the character of Mary Magdalene by offering a different story based on Gnostic texts. Thus, Roberts employs postmodern strategies and reveals an interweaving between Literature and History as discursive practices.

Keywords: Postmodernism; Gender; Religion; Michèle Roberts.

Ao discutir as contradições nos discursos de dominação e resistência nos estudos feministas, a historiadora Linda Gordon diz que a história das mulheres se dá contra a história dos homens. (GORDON, 1986) Gordon expõe que, a partir de instituições heterossexuais - econômica, educacional, cultural e comercial - criam-se diferenças que são ora valorizadas ora ignoradas. Como pesquisadora da história, Gordon ressalta que apenas usar o termo herstory para enfatizar um movimento recente que se preocupa com a história das mulheres não é o suficiente: o que se faz necessário é validar todas as práticas já existentes desde o século XIX, como o trabalho The Woman's Bible de Elizabeth Cady Stanton no qual a subserviência feminina é questionada nas escrituras religiosas.

Longe de invalidar esforços recentes em relação ao campo de estudos feministas, Gordon aponta que ainda há questões epistemológicas latentes em relação ao campo da história, política e literatura. O que sobressai no texto de Gordon é a preocupação de que se faz necessária ainda uma crítica (literária) que possa desafiar a estrutura dos mencionados campos e como outras áreas como Estudos Feministas ou Psicologia Feminina precisam ser repensadas para além de simples disciplinas acadêmicas. (GORDON, 1986, p. 27) É nessa interseção entre história, política e literatura que muitas produções artísticas - livros, filmes,

\footnotetext{
${ }^{1}$ Doutorando em Estudos da Literatura na Universidade Federal Fluminense (UFF). Professor Assistente de Língua Inglesa e Literaturas de Língua Inglesa na Universidade Estadual do Piauí. Endereço eletrônico: ruan.nunes@,hotmail.com
} 
pinturas etc - têm questionado o cânone com o intuito não de criar um novo centro, mas sim de alimentar a percepção das beiradas como lócus de produções epistêmicas também. É exatamente esta perspectiva crítica que Gordon explora ao ressaltar que os feminismos podem, na ausência de uma palavra melhor, empoderar os sujeitos marginalizados dos discursos oficiais. "Transcender esta improdutiva polarização requer", segundo Gordon "que integremos ao debate uma crítica da definição do político." (1986, p. 25) Portanto, falar sobre o político significa falar sobre relações de poder e, mais importante, sobre como essas relações são políticas.

Uma estratégia coerente com a preocupação de Gordon é a ficcionalização de textos canônicos, em especial aqueles que servem de base para construção de hierarquias sociais, tais como os religiosos e históricos. Romances contemporâneos como Burial Rites de Hannah Kent, The Passion of Artemisia de Susan Vreeland e Alias Grace de Margaret Atwood ilustram como registros oficiais e históricos têm sido apropriados e re-visionados (no sentido de Adrienne Rich em releituras como re-visão) com fins políticos: escutar a voz daqueles sujeitos cujas histórias foram apagadas ou modificadas. Escritos por mulheres de diferentes países como Austrália, Estados Unidos e Canadá, os romances citados exemplificam como os discursos oficiais são, na realidade, também uma leitura daquilo que se convencionou chamar de história (como campo disciplinar), portanto, a questão que fomenta a leitura daqueles é - qual o outro lado da moeda? - se torna essencial para compreender a história como uma construção.

A partir de uma perspectiva feminista que entrelaça o discurso religioso com a literatura, o romance The Secret Gospel of Mary Magdalene da inglesa Michèle Roberts foi escolhido para ilustrar não só a discussão da estratégia pós-moderna da releitura do passado enquanto invenção/ficcionalização, mas também temas caros como identidade e gênero.

É importante notar que o romance se apropria de uma narrativa totalizante para desmistificar a metanarrativa bíblica. Partindo de pressupostos pós-modernos, é interessante lembrar o que a crítica canadense Linda Hutcheon diz sobre o termo "totalizar":

[ele] não significa apenas unificar, mas sim unificar com a vista ao poder e ao controle, e, como tal, esse termo aponta para as relações ocultas de poder que estão por trás dos nossos sistemas humanista e positivista para a unificação de materiais distintos, sejam estéticos ou científicos. (HUTCHEON, 1991, p.13)

Hutcheon aponta para o valor de controle que subjaz aquelas narrativas descritas como totalizantes, tais como a Bíblia ou o Alcorão. Assim, o pós-modernismo "questiona sistemas centralizados, totalizados, hierarquizados e fechados.” (HUTCHEON, 1991, p. 65), porém ele admite a necessidade de uma ordem - uma que não seja baseada em conceitos como naturais ou preexistentes.

Ao descrever a relação entre história e literatura, Hutcheon descreve a metaficção historiográfica como uma forma mais "paradoxal e historicamente complexa", pois ela problematiza a noção de conhecimento histórico. Reconhecendo a história e a literatura como discursos, a metaficção historiográfica reposiciona o que se convencionou chamar de fatos históricos a partir da premissa que estes fatos só nos são conhecidos através de narrativas que, por sua vez, foram criadas a partir de um posicionamento. Logo, a escrita da história é vista também como uma construção e que a ficção pós-moderna pode se ocupar de oferecer não uma Verdade (com V maiúsculo), mas sim várias verdades - "A metaficção historiográfica adota uma ideologia pós-moderna de pluralidade e reconhecimento da diferença.” (HUTCHEON, 1991, p. 151) 
Ao se aproveitar das verdades (e mentiras) do registro histórico, as ficções pósmodernas, especialmente as metaficções historiográficas, problematizam as noções de história através da literatura, colocando que não se pode mais pensar que a primeira trata da realidade e a segunda do campo fantasioso. Dessa forma, não é casual que exista uma ligação entre feminismos e pós-modernismo, afinal, ambos discutem a posição de sujeitos ex-cêntricos que almejam questionar o centro. Entretanto, não buscam reposicionar as margens como um novo centro, mas sim politizar a leitura dessas margens como fontes tão importantes como o centro canônico.

Em The Politics of Postmodernism, Hutcheon argumenta que não se pode mais pensar se a questão seria os vários feminismos impactando de maneira relevante o pós-modernismo, uma vez que essa intersecção é clara, mas que se deve investigar como as estratégias pósmodernas podem ser implementadas por artistas feministas para fins desconstrutivos. (HUTCHEON, 2002, p. 145) Ao relacionar pós-modernismo e feminismos, Hutcheon deixa claro o primeiro tem um papel fundamental para que compreendamos os modos de representação dominantes na cultural ocidental, porém ela ressalta que são os feminismos que privilegiam a representação da mulher como sujeito através de questionamentos como a reescrita e o revisionismo.

São os feminismos que colocam em xeque a compreensão da mulher como algo inato e imutável. Após a segunda onda feminista, leituras que privilegiam esta discussão teórica passaram a enxergar que gênero é uma categoria construída. Segundo a psicanalista e ativista trans Letícia Lanz, gênero é "um dispositivo de classificação, hierarquização e controle social dos seres humanos, baseado exclusivamente no seu sexo genital.” (LANZ, 2015, p. 410) Lanz ainda reforça que gênero é construído socialmente a partir de "papéis sociais, oportunidades e interdições, atitudes psicossomáticas e atribuições políticas, econômicas e culturais" (idem) que são compulsoriamente impostas a cada indivíduo. Desse modo, é possível perceber que não existe gênero universal e que este se forma a partir de um condicionamento. Mais uma vez evocando Hutcheon, qualquer narrativa totalizante e/ou totalizadora busca unificar "com vista ao poder", ou seja, bebendo do texto de Michèle Roberts, por que permitir que exista um evangelho que afirme que o mundo surgiu de uma mulher e não de um deus masculino? E mais, onde mora o perigo de permitir que Maria Madalena tenha voz para contradizer a formação masculina dos apóstolos/discípulos de Jesus? Ao silenciar Maria Madalena nas escrituras religiosas e invalidar o texto gnóstico que pode ser encontrado no Nag Hammadi, existiria algum propósito de totalizar o discurso com fins desconhecidos? É nesta brecha que Michèle Roberts insere a sua narrativa sobre o evangelho de Maria Madalena, dando visibilidade e voz àquela previamente alienada como prostituta.

Embora esteja discutindo personagens femininas em romances brasileiros, a afirmação de Ruth Silviano Brandão em A Mulher Escrita acerca da alienação da mulher ilustra a hierarquia gendrada que Roberts busca desestruturar. Brandão afirma que é possível notar um jogo de espelhos "em que à personagem feminina cabem duas soluções: ou refletir a imagem masculina, metonímia e metáfora de uma ideologia opressora, ou perder-se no vazio da loucura e da marginalização.” (BRANCO \& BRANDÃO, 2004, p. 56) O que acontece, então, quando as personagens femininas não se encaixam nestas duas soluções? Pode-se argumentar que é possível para a personagem feminina no pós-modernismo, em especial aquelas ligadas ao mundo religioso, tão hierárquico e opressor, utilizar a sua voz para não ser marginalizada ou se tornar a imagem do discurso masculino.

Já que é pela linguagem que se instaura toda forma de poder (BRANCO \& BRANDÃO, 2004, p. 44), é essencial questionar como formas de discurso perpetuam um sistema 
moral centrado na figura masculina como fonte para a mulher. Entre os discursos de poder, temos não só o religioso, mas também o literário e o ideológico, todos importantes nessa discussão, especialmente considerando a compreensão de gênero nestes campos. As personagens femininas foram previamente não apenas silenciadas, mas moldadas ao fitar masculino (male gaze) e dotadas de uma identidade fixa e imutável: a puta, a mãe, a santa, a pecadora. Todas essas concepções binárias serviram - infelizmente servem ainda - como instrumentos de opressão e silenciamento:

a mulher está sujeita a um sistema moral de que ela participa de forma passiva, na medida em que não detém a palavra, mas, ao contrário, é falada, repetidora de um discurso do qual não é o sujeito. Esse discurso exterior articula a questão da sexualidade feminina, em uma sociedade patriarcal, em que a mulher não ocupa um lugar privilegiado. (BRANCO \& BRANDÃO, 2004, p. 44)

O discurso literário não é inocente na produção desse sistema moral que Branco \& Brandão citam. Portanto, é producente analisar quão cúmplice de discursos excludentes as obras literárias foram ou ainda são, especialmente ao centrar a análise das personagens femininas a partir de uma identificação com a teoria feminista. Segundo Vera Queiroz (1997), a análise de objetos culturais a partir de uma ótica que privilegie gênero oferece uma oportunidade de questionar a estrutura excludente:

Olhar a produção e a recepção dos objetos da cultura (ocidental, patriarcal) sob a ótica das relações de gênero implica pôr em questão a centralidade do sujeito masculino como ponto de referência a partir de onde são avaliados, julgados e definidos como os valores de tal cultura, o que tem significado para a mulher, o Outro do masculino, uma posição hierarquicamente inferior quanto aos atributos (e às atribuições) que lhe são socialmente conferidos. (QUEIROZ, 1997, p. 104)

Na citação acima, Queiroz explora o X da questão: o gênero masculino tem sido preponderante e se tornou o modelo central para a avaliação. O masculino se tornou não só o padrão, mas também se tornou aquele com o poder de decidir sobre o mundo. Isso se evidencia no romance de Roberts com a decisão de Simão Pedro de que mulheres não poderiam participar das jornadas dos apóstolos. Maria Madalena questiona sobre o porquê de não poder ser também uma integrante do grupo dos apóstolos, uma vez que Jesus também se revelara para ela:

What you really mean, Simon Peter, is that because I am unmarried and have chosen to live and love freely I am a threat to your ideas of what a woman disciple should be. (...) Do you really mean that there can be no place for me in your company if I am neither virgin nor wife? You call me a witch, but I know what you mean. Free woman. Whore. (ROBERTS, 2007, p. 133)

O trecho acima ilustra uma reação de Maria Madalena que coloca a discussão de gênero em destaque. Ao questionar se ela, uma mulher que tampouco era virgem ou casada, não poderia ser parte do grupo de discípulos de Jesus, Maria Madalena evidencia a construção de mulher da época: virginal e pura. Caso destoasse desse modelo religioso, ela se torna uma ameaça, pois estaria "fora do controle".

Publicado sob o título The Wild Girl em 1984, o romance seria republicado mais tarde com outro título, The Secret Gospel of Mary Magdalene. No prefácio da edição de 2006, Roberts 
explica que escreveu o este livro movida por questões que a assombravam. Fazendo referência ao mundo religioso no qual fora criada e subseqüente quebra com este, Roberts enfatiza que buscava compreender o porquê da igreja, dominada por homens, colocar as mulheres em oposições binárias, sagradas mães assexuadas ou vagabundas sensuais más. Para refletir sobre esta questão, Roberts decide então voltar aos textos canônicos para narrar o evangelho que Maria Madalena teria escrito se apoiando em textos gnósticos conhecidos como Nag Hammadi. Considerando a natureza fragmentária desses textos, Roberts concebe a ficção de sua obra, porém fazendo constante referência ao material do Nag Hammadi para criar a sua metaficção historiográfica.

$\mathrm{Na}$ obra de Roberts, Maria Madalena nasceu em Betânia onde residia com seus pais e irmãos, Martha e Lázaro. Ela narra que gostava de subir no telhado na infância para admirar as estrelas e pensar sobre o seu verdadeiro lar que estava atrás da escuridão do céu noturno. Entretanto, a inocência infantil termina quando ela tem sua primeira menstruação que vem junto com regras e proibições: nada mais de dormir no telhado, olhar sempre para baixo e conhecer a fé através do seu irmão, uma vez que ela não poderia jamais estudar - "God was mediated to me, as to my older sister Martha, through the words of my father amd brother in the confines o four home, and, outside, through the authority of four village priests and our rules." (ROBERTS, 2007, p. 12)

Após a morte de sua mãe, Maria Madalena decide fugir e vai parar na cidade de Alexandria. No caminho ela é estuprada por mercadores que, inicialmente, haviam oferecido ajuda e apoio. Ironicamente, Madalena afirma que fora brutalizada, mas que agora estava livre, já que nenhum homem na sua vila a aceitaria como esposa. A partir desse momento, ela oferece seu corpo como pagamento até chegar em Alexandria, onde conhece Sybilla, uma hetaira, que a acolhe e com quem nutre uma relação lésbica.

Conforme o início do romance atesta, a preocupação de Roberts é tentar humanizar as condições gendradas na qual Madalena se encontrava. A fuga de um ambiente extremamente patriarcal com a esperança de uma vida diferente a leva para o que a religião chamará de ruína, afinal, o corpo como o templo da alma fora profanado. Entretanto, ao colocar Sybilla, uma prostituta de luxo para cuidar de Madalena, Roberts evidencia o caráter de união entre mulheres em um mundo em que homens tudo limitam.

She became my mother, sister and friend as well as my mistress. She taught me to read and write the Greek scripts, she encouraged me to practise my singing and dancing, she instructed me in the arts of conversation and dalliance, the arrangement of hair and clothes, the exercise of the mind. All this was pleasant to me. (ROBERTS, 2007, p. 19-20)

A noção de uma mulher letrada, independente e que sente prazer no que faz suscita um questionamento do ideal religioso que molda a mulher que evidencia a construção de gênero. A criação de Madalena tem uma raiz feminista em que ela pode subverter a relação de poder se tornando uma voz dissonante que tem controle sobre si. Falar sobre sua sexualidade em pleno século XXI ainda é um tabu em determinados círculos, logo uma mulher segura de sua sexualidade como Maria Madalena era uma ameaça ao ideal de mulher religiosa.

Com saudades de seu lar e sua família, Madalena retorna e passa a morar com seus irmãos após a morte de seu pai. Lázaro tem problemas com alcoolismo e trata Martha como uma escrava. Enxergando a dificuldade financeira da casa, Madalena continua a se prostituir para conseguir dinheiro para ajudar a família, evidenciando o caráter hipócrita da sociedade de Betânia. Um dia ela conhece Jesus e outros rapazes que Lázaro traz para comer e beber 
em sua casa e a partir dali o enredo demonstra a ligação amorosa e sexual entre Jesus e Madalena.

Uma cena extremamente irônica que questiona as habilidades sobre-humanas de Jesus é a morte de Lázaro. Como conseqüência de seus hábitos, este fica muito doente quando Jesus está longe, fato que Madalena e a irmã acreditam que poderia ajudá-lo a se recuperar. Entretanto, com a piora de seu irmão, Madalena decide preparar, em segredo com sua irmã, uma poção medicinal que aprendera com os serventes em Alexandria para curar doenças. Após o culto que envolve ervas e um discurso que quebra com a noção religiosa, Lázaro é colocado na tumba em que Jesus o encontrará e receberá a gloria de tê-lo ressuscitado. A construção de Roberts evidencia o jogo entre religião e mágica em um mundo em que o primeiro é aceito e o segundo renegado pelas autoridades que temiam perder o seu poder.

A relação de Jesus e Madalena se torna um objeto de inveja entre os discípulos, especialmente a figura de Simão Pedro, com quem Madalena tem embates ideológicos. Quebrando com a noção de uma religião punitiva, Madalena apresenta um Jesus que a respeita e nutre admiração pelas mulheres, com maneiras que a fizeram inicialmente duvidar de sua personalidade. Em The Secret Gospel of Mary Magdalene, Simão Pedro se torna uma figura cruel que, apesar de seus erros, é perdoado por Madalena. Mesmo assim, Simão Pedro não teme explicitar as regras de sua população que afirma que as mulheres devem aprender com os homens e não podem pregar em público, além de reiterar que as mulheres são a porta de entrada para o mal e a morte.

Dont you know? That women are the gateway to evil and death? It's written in the sacred texts: the creation of man followed that of the earth, and the woman followed the man, and marriage followed the woman, and reproduction followed marriage, and death followed reproduction. (ROBERTS, 2007, p. 62)

A crítica de Roberts revela como gênero é construído: por Madalena ser uma mulher, ela teria apenas a função materna reprodutiva, logo, ela deveria ter filhos e servir ao seu lar. Após a crucificação e ressurreição de Jesus, Maria Madalena tem um novo embate com Simão Pedro que recusa aceitar mulheres pregando a palavra cristã e que decide que os votos do grupo serão a forma democrática de permitir ou não mulheres como parte do grupo dos apóstolos. Com a maioria dos votantes do sexo masculino, o resultado foi negativo e apenas as três mulheres presentes - Madalena, Martha, Maria, mãe de Cristo, e Salomé - votaram pelo direito feminino de pregar.

And so it became decided that the Son of the Father would be reflected in a male priesthood, and that the Daughters of the Father could continue to preach and to prophesy, within certain carefully established limits, and to serve the new church in the many and important ways in which woman served their husbands and families. (ROBERTS, 2007, p. 134)

O direito de peregrinar e pregar é negado com base em como a cultura enxerga a mulher, ou seja, uma questão de gênero. Ser mulher significa ficar em casa, cuidando dos filhos e do lar. A mulher poderia pregar, porém dentro de certos limites e contanto que o seu lar fosse privilegiado e colocado em primeiro lugar. A hipocrisia velada se dá através dos argumentos que pregam a igualdade de todos - "Aos olhos de Deus somos todos iguais" porém que se tornam práticas excludentes que perpetuam uma definição única da mulher, como no trecho abaixo de Simão Pedro: 
Amongst disciples, He said: there is no male and no female. In the eyes of God all of us are equal, man and woman, slave and master, as Jesus taught, for all of us have souls and all of us are called to redemption. But at the same time we live in the world, a wicked and corrupt world where women are at risk of being exploited or abused by sinful women. How can we allow our sisters to go about in public and expose themselves to this danger? (ROBERTS, 2007, p. 131)

Através de palavras que, supostamente, evidenciam a preocupação com as mulheres, Simão Pedro sublinha que elas não têm poder de decisão nesse mundo e que caberá aos homens institucionalizar suas ideias e interpretações. É esse mundo masculino que a escrita de Roberts busca descentrar ao oferecer uma personagem complexa como Maria Madalena.

Em estudo sobre religião e gênero, Cristina Maria Teixeira e Wiliam Alves Biserra apontam que "toda história é história de rupturas, de escolhas, de apropriações e de silêncios" (2012, p. 43). Ao misturar literatura e religião, Roberts não busca identificar um vazio que procura preencher, mas sim enfatizar a existência dessas brechas nas histórias. Ao contestar a leitura de Maria Madalena dentro de binarismos, Roberts evidencia um papel político na interpretação da referida personagem: não se pode pensar em diminuir Madalena a uma prostituta apenas, afinal, ela não é só isso, como se sua identidade fosse fixa e imutável.

A estratégia de Roberts pode ser lida como uma contestação do paradigma religioso que parece ansiar por manter determinadas estruturas binárias em seu lugar. Conforme apontado por Teixeira e Biserra:

Uma contradição notória é a de que as mulheres objetificadas pelo olhar literário masculino, ou seja, as personagens femininas dos grandes autores são, muitas vezes, poderosas, persuasivas, corajosas; entretanto, na igualmente patriarcal voz da historiografia tradicional, com poucas exceções, as mulheres eram representadas como fiéis e obedientes aos seus maridos, servas de seus pais além de boas e pacientes mães de seus filhos. (TEIXEIRA \& BISERRA, 2012, p. 16)

Ao buscar reconstruir a história de uma mulher forte como Maria Madalena, cuja história tem sido constantemente distorcida, Roberts "viola" uma representação do passado para desconstruir a própria noção deste mesmo passado. Ao demonstrar que essa história é uma representação que difere da outra já canonizada nos textos bíblicos, Roberts evidencia quão importante é a própria consciência do texto como produto discursivo. $\mathrm{O}$ projeto de Roberts corrobora as palavras de Linda Hutcheon em The Politics of Postmodernism: a representação pós-moderna contesta qualquer projeto totalizante ao desmascarar seus poderes e suas limitações. (2002, p. 35)

Concluindo, percebe-se que The Secret Gospel of Mary Magdalene, mais que um romance feminista, é uma obra pós-moderna que incorpora uma preocupação sobre a questão dos discursos religiosos como únicos e inquestionáveis. Entrelaçando história, política e literatura, Roberts narra a vida de Maria Madalena sob uma ótica que privilegia gênero como categoria fundamental para debater a posição daquela. Não por acaso, as palavras de Joan Scott caem como uma luva: A narrativa da história das mulheres "é sempre uma narrativa política." (SCOTT, 2011, p. 69) A história de Maria Madalena é, portanto, uma narrativa política.

\section{Referências}

BRANCO, Lucia Castello \& BRANDÃO, Ruth Silviano. A mulher escrita. Rio de Janeiro:

https://periodicos.unifap.br/index.php/letras

Macapá, v. 8, n. 3, $2^{\circ}$ sem., 2018 
Lamparina Editora, 2004.

GORDON, Linda. What's new in Women's History. In: Teresa de Lauretis, ed. Feminist studies: critical studies. Bloomington, Indiana University Press, 1986, p.2030.

HUTCHEON, Linda. Poética do pós-modernismo: história, teoria, ficção. Rio de Janeiro: Imago, 1991.

HUTCHEON, Linda. The Politics of potmodernism. London: Routledge, 2002.

LANZ, Letícia. O corpo da roupa. Curitiba: Transgente, 2015.

QUEIROZ, Vera. Crítica literária e estratégias de gênero. Niterói: EdUFF, 1997.

ROBERTS, Michèle. The secret gospel of Mary Magdalene. London: Vintage, 2007.

SCOT'T, Joan. História das mulheres. In: Peter Burke, org. A escrita da história: novas perspectivas. São Paulo, Editora Unesp, 2011, p. 40-98.

TEIXEIRA, Cristina Maria \& BISERRA, Wiliam Alves. Santas impossíveis: religião e gênero na literatura contemporânea. Brasília: Editora UNB, 2012. 